\title{
LA RECEPCIÓN DE LAS TRADICIONES DE JACOB EN OSEAS 12
}

\author{
Algunas dificultades*
}

\section{Introducción}

La imagen del "amor esponsal" en cuanto reveladora del misterio del amor de Dios por su pueblo -indudablemente distintiva en la predicación del profeta Oseas- es a la vez, con sus innumerables matices, provocadora y sugestiva. Hace pensar. Una vez incorporada al horizonte de la propia reflexión, difícilmente deje de mantenernos atentos a su posible presencia. Es que, en su atractiva simpleza y luminosa densidad, impulsa a tratar de (empezar a) comprender "cómo es" que "ama Dios".

Este tema me había ocupado largamente hace unos años al intentar elaborarlo para un trabajo ordenado a la obtención del grado de Licenciatura en Teología con especialización en Sagradas Escrituras ${ }^{1}$. Desde entonces, la pregunta por "el estilo del amor de Dios" y "el mandato de amar cómo ama Él" -particularmente en cuanto expresado en "clave" de amor esponsal- no dejó de inquietarme, de motivarme, y, casi sin quererlo, comenzaba a iluminar de una manera nueva el enfoque de lectura de otros textos en otros contextos.

* El presente artículo fue presentado como comunicación en la I Semana Bíblica Argentina, que tuvo lugar en Buenos Aires del 26 al 28 de mayo de 2011.

1 Corría el año 1998 y la disertación se tituló: "Ama como ama Yahweh". Una aproximación a 0s 3,1-5 desde el análisis de la composición". Una síntesis de ese trabajo fue publicada con el título " «Ama como ama Yahweh...» (Os 3,1). ¿Agrio sarcasmo o amor purificador?” en: J. L. D’Amico - E. DE LA SERna (coord.), “Donde está el Espíritu del Señor está la libertad". Homenaje a Luis Heriberto Rivas con motivo de sus 70 años, Buenos Aires, 2003, 117-144. 
Así fue como en una ocasión, mientras reflexionaba sobre las tradiciones "patriarcales" del libro del Génesis, tantas veces leídas, reparé por primera vez en la diferencia respecto del "comportamiento esponsal" que mostraba el "astuto y tramposo" patriarca Jacob respecto de sus ilustres antepasados Abraham e Isaac, quienes, para enriquecerse o, al menos, por temor a ser maltratados o asesinados, hicieron pasar a sus respectivas esposas como hermanas, entregándolas a otros hombres ${ }^{2}$.

Jacob, en cambio, movido por un intenso amor (cf. Gn 29,18.20), trabajó duramente largos años para poder lograr desposarse y construir -a pesar de las resistencias y permanentes trabas que iba poniendo sucesivamente su no menos tramposo suegro- una familia propia con la mujer que amaba (cf. Gn 29,15-30).

Este aspecto del comportamiento "conyugal" de "los patriarcas" me resultaba llamativamente heterogéneo, y despertó mi curiosidad, moviéndome a reconsiderar la compleja (y -a mi juicio y en principio- bastante antipática) figura de Jacob.

Entrelazadas estas dos inquietudes -esto es, el misterioso "estilo" del amor de Dios expresado en lenguaje esponsal (tan propio del desarrollo teológico de Oseas) y el peculiar "comportamiento conyugal" de Jacob (conocido sobre todo por los relatos del Génesis)- parecía inevitable confluir directa y naturalmente en el capítulo 12 de Oseas, que, en el marco de una obra atravesada axialmente por categorías conyugales, reveladoras de la eficacia transformante del amor divino de tipo "esponsal", alude de manera explícita a la controvertida figura del patriarca Jacob y mencionando, "como al pasar", lo que el antepasado epónimo "hizo" "por una mujer" (Os 12,13a).

Todo ello iba motivándome progresivamente a considerar si el profeta Oseas, implacablemente crítico de las tradiciones nacionales pero, a la vez, profundamente convencido de lo que puede lograr en su díscola amada (sólo) el "amor" -esponsal- de Dios, no habría quizá "visto" en el "caso Jacob" otro "ejemplo" esperanzador, revelador de como otra vida también díscola, emblemática -la del que toma nombre la no menos díscola nación- marcada hasta entonces, según narran aparentemente los relatos del Génesis, por adquisiciones fraudulentas, habría sido reorientada a partir de una honda experiencia de un amor que pretendía ser conyugal, de adquisiciones legítimas, soportando -no construyendo- fraudes, y que le habría

${ }^{2}$ Cf. Gn 12,10-20; 20 y 26,1-11. La motivación respectiva para actuar de esa manera aparece explícita en los tres textos bíblicos en los versículos 12,13, 20,11 y $26,7.9$. 
enseñado casi sin quererlo, por el dinamismo propio del amor auténtico, a "amar como ama Dios".

Así iniciaba un recorrido personal en búsqueda de una respuesta que sólo el texto oseano podría ofrecer acabadamente. Tras muchas vacilaciones y consultas, trazaba un "itinerario de investigación", un tramo del cual ofrezco a continuación, comentando algunos de sus "ítems" brevemente (1).

Sobre la base de este tramo del "itinerario de investigación", me propongo en esta comunicación presentar -a modo de status quaestionis y en el contexto más amplio de la recepción oseana de las tradiciones de Jacobla problemática acerca de la presunta influencia que la versión de la tradición de Jacob que conocemos por el libro del Génesis habría tenido -o noal momento de la composición del texto oseano, y, en consecuencia, si es pertinente y hasta dónde - o no- tenerla en cuenta al momento de interpretar el pasaje en cuestión (2).

\section{Un tramo - a manera de esquema, brevemente comentado- del "itinerario de investigación"}

\section{La recepción de las tradiciones de Jacob en Oseas $12^{3}$}

1. La posibilidad de acceder a tradiciones pre-exílicas ${ }^{4}$.

2. Dificultades de lectura del capítulo 12 de Oseas.

2.1. Las propuestas de delimitación, sub-división y reordena-miento de la unidad son considerablemente variadas.

\footnotetext{
${ }^{3}$ Ya que intentamos investigar "la recepción oseana de las tradiciones de Jacob" -en particular, enfocada desde una hipotética relectura de las mismas en clave de “amor conyugal" - habrá que tener en cuenta por lo menos dos cuestiones previas y/o concomitantes. Ya que se trata de una "recepción" cabe preguntarse primero si es posible efectivamente acceder a dichas tradiciones y cómo lograrlo y, de ser así, -y en segundo lugar- para poder calibrar los contornos de la relectura oseana, procurar establecer cuáles son específicamente las tradiciones que presuntamente estaría reelaborando Oseas en su recepción de la figura de Jacob.

${ }^{4}$ El uso que los profetas hacen de las tradiciones pre-exílicas lincluso premonárquicas) ha atraído la atención de los investigadores -particularmente los especializados en métodos histórico-críticos- en el seno del debate a propósito de la presunta antigüedad de las mismas. En este horizonte, el Libro de Oseas resulta especialmente atractivo, tanto por su supuesta antigüedad ly en consecuencia, porque aparentemente no estaría "contaminado" de "deuteronomismo"), como por contener múltiples y claras referencias a los "patriarcas", a las tradiciones del "desierto" y de la "salida de Egipto", a diversas tradiciones del ciclo llamado de la “conquista”. Y en particular, el (o los) oráculo(s) del capítulo 12 de Oseas se ha(n) transformado casi en un lugar obligado a la hora de investigar la posible existencia
} 
2.2. No hay acuerdo a propósito de la determinación del Género literario del capítulo.

2.3. Desde la perspectiva de la Historia de la Redacción se discuten tanto los alcances de una generalmente admitida "relectura judía" posterior como la magnitud de una hipotética intervención de "glosadores" como la presunta "antigüedad" de algunos segmentos de la unidad.

2.4. Numerosos términos y expresiones del pasaje resultan difíciles de interpretar:

Sea porque los referentes de los pronombres resultan ambiguos o no queda muy claro cuáles son los sujetos de los verbos.

Sea porque emplean construcciones inusuales.

Sea porque resulta difícil decidir qué significado de los posibles cuadra mejor.

3. Jacob en Oseas 12.

La dificultad por procurar precisar el rol que juegan las diversas referencias a Jacob a lo largo del pasaje ha suscitado un apreciable debate, en el que no es sencillo encontrar grandes consensos.

$\mathrm{Al}$ recorrer la bibliografía especializada se observan variantes significativas:

3.1. Al momento de determinar qué escenas de la vida de Jacob son aludidas en Oseas $12^{5}$.

3.2. Al concluir si Oseas tuvo acceso a las tradiciones hoy conocidas por el texto actual del Génesis o si manejó una tradición diferente.

de tradiciones patriarcales (y mosaicas) anteriores a la composición del Pentateuco. Dice E. K. Holt, Prophesying the Past. The Use of Israel's History in the Book of Hosea, Sheffield, JSOT.S 194 - 1995, 18-19: "If modern Penthateuchal criticism is right ...then the Book of Hosea presents the earliest written fixation of the traditions of Jacob and of Israel's past".

${ }^{5}$ Se coincide en general en reconocer que en 0 s 12,4-5.13 se alude explícitamente:

En 12,4a, la escena de los dos hermanos en el vientre de su madre (cf. Gn 25,26). Pero no hay coincidencias al indicar si -en el vientre de su madre- Jacob agarra a su hermano (del talón) o si suplanta a su hermano o si defrauda a su hermano.

En 12,4b.5a, a la escena en "Penuel" (cf. Gn 32,23-33). Pero no hay coincidencias al indicar si -en Penuel- Jacob luchó con Dios o si luchó con un ángel o si fue Dios quién luchó. Tampoco se coincide al momento de indicar quien "venció" ni quién "lloró y suplicó".

En 12,5b, a la (primera) escena de Jacob en Betel (cf. Gn 28,13). Pero no hay coincidencias al indicar -en la primera escena en Betel-quién encuentra a quién 0 quién habló con quién (si "Yahweh" habló con "Jacob" o si habló con "nosotros"; si fue "Jacob" quien habló o si el que habló fue "el dios Bethel"). Tampoco faltan quienes ven aquí una alusión a la "segunda" escena de Jacob en Betel lla narrada en Génesis 35). 
3.3. En descubrir cuál es el perfil de Jacob que surge o prevalece en el material que introduce y/o reelabora Oseas ${ }^{6}$ :

- Con rasgos -más o menos acusadamente- negativos. Como puramente "tramposo", "mentiroso", "estafador". Vinculado a alguna realidad negativa o polémica que el autor de Os 12 buscaría combatir?.

- Con rasgos a la vez negativos y positivos. Ya que habría material primario oseano (negativo) y secundario redaccional (positivo) ${ }^{8}$.

En 12,13a, su presencia en Aram (cf. Gn 27,43). Pero no hay coincidencias al indicar si Jacob simplemente "se fue" a Aram o si “huyó" a Aram o, inclusive, si huyó "de Aram".

En 12,13b, a su servicio y "guarda" bajo las órdenes de su suegro (cf. Génesis 29,15-30). Pero no hay coincidencias al momento de determinar: (a) a quién sirvió en Aram, si a Labán o a "otros dioses"; (b) qué clase de servicio prestó (¿sometimiento indigno? ¿prostitución cultual? ¿servicio por amor?); (c) si guardó “rebaños” o ḥesed ûmišpāț o "la palabra dada"; (d) si sirvió por dos mujeres o por una.

No pocos investigadores estiman posible encontrar otras alusiones a las tradiciones de Jacob, más o menos implícitas, en otros versículos del capítulo. Por ejemplo, según E. Good, "Hosea and the Jacob Tradition", VT 16 - 1996, 149, Oseas habría mencionado cinco "incidentes" de la vida de Jacob; el tercero se referiría a un "incidente" que incluiría un "llanto" y que habría llevado a poner nombre a un lugar. Good se refiere, a propósito de la referencia al "llanto" en 12,5a, a la escena de la muerte y sepultura bajo la "encina del llanto" de Débora, la nodriza de Rebeca mencionada en Génesis 35,8. Otros intérpretes entienden que en 12,9 habría una alusión al enriquecimiento por lo menos ambiguo (si no tramposo) de Jacob cuando servía a Labán.

${ }^{6}$ Es curioso constatar, cuando se recorre la bibliografía especializada, que todo lo que se dice de Jacob en Os 12 ha podido ser entendido tanto en favor del patriarca como en su contra.

${ }^{7}$ Por ejemplo, (1) Determinado tipo de culto en Betel -santuario real del Reino del Norte- o directamente al "dios de Betel"; (2) A Jacob en cuanto referente de la propia identidad, en el marco de una presunta polémica por los rasgos esenciales de la identidad nacional tal como surge de las "leyendas de origen".

${ }^{8}$ Así desde la Literarkritik y desde la Redaktionskritik. Bernhard Duнm-según quien los profetas habrían sido renovadores radicales- entendía, por ejemplo, que Oseas en realidad procuraba burlarse de las tradiciones populares referidas al patriarca y habría intentado reinterpretarlas en consonancia con las demandas del "monoteísmo ético". En un período posterior, cuando las historias patriarcales habrían sido completamente integradas con las tradiciones del Sinaí, un redactor habría mitigado la descripción oseana, tan poco favorable al patriarca, mediante la inserción de algunos elementos positivos en la obra original del profeta (B. DuHM, “Anmerkungen zu den zwölf Propheten", ZAW 31 - 1911, 37-39). Más recientemente, G. YEE atribuía los elementos positivos a un redactor post-exílico. 
Theodorus Vriezen propuso entender el capítulo en forma de un diálogo entre el profeta y su audiencia, en el que el primero estaría ridiculizando a Jacob mientras que los últimos procurarían defenderlo9 .

- Con cambios significativos de comportamiento conforme avanza el desarrollo de la unidad.

Jacob comenzaría siendo presentado como "tramposo" pero a lo largo del recorrido se lo vería implicado en un proceso (exitoso) de conversión ${ }^{10}$.

- Con rasgos -más o menos acusadamente- positivos.

Según Peter Ackroyd, Oseas no estaría criticando al ancestro nacional sino más bien intentaría insistir en el carácter misterioso de la acción divina, de la que Jacob habría sido objeto y tipo. El recurso a las alusiones a la figura de Jacob apuntaría más bien a mostrar un "prolegómeno" al más grande acto de liberación divina, indicado en los acontecimientos del Éxodo aludidos en el versículo 12,14 .

Para Heinz Neef, Oseas estaría presentando al patriarca ante su pueblo como a alguien que buscó persistentemente a Dios y lo encontró, que mantuvo intacta su relación con Dios, constituyendo un comienzo plenamente salvífico.

- Sin pretender valorar moralmente sus comportamientos.

Para Francis Andersen y David Freedman ni el narrador del génesis ni Oseas asumen una perspectiva "moralizante". La figura de Jacob sería enigmática desde un punto de vista moral; no se pretendería evaluarlo ni establecer una comparación con el Israel contemporáneo al profeta.

Para Santiago Ausín, "la figura de Jacob evocada por Oseas carece de toda connotación moral: ni es el viejo modelo al que el pueblo contemporáneo a Oseas debe imitar, ni es el ancestro ini-

\footnotetext{
${ }^{9}$ Según T. VRIEZEN, la visión del profeta sobre Jacob resulta totalmente negativa y opuesta a la versión de Génesis.

${ }^{10}$ Por ejemplo, L. Eslinger, "Hosea 12:5a and Genesis 32:29. A Study in Inner Biblical Exegesis", JSOT 18 - 1980, 94 discierne una estructura quiástica entre los vv. 12,3-5 cuyo punto de inflexión lo constituiría “el juicio de Dios que conmina a un cambio de vida" de 12,5a. Desde allí, el Jacob del texto comenzaría a dar los pasos en un camino de conversión que lo llevarán hacia la reconciliación con su Dios en el marco de la Alianza (12,5b). El patriarca no sólo “guardó ovejas" (12,13) sino también hesed ûmišpāt, y así el relato se transformaría en un "paradigma de la conversión".
} 
cuo cuyos fraudes debe evitar... Jacob, tanto en el Génesis como en Oseas, de suyo, era como los demás, con cualidades y con limitaciones, con triunfos y con derrotas... Pero Dios siempre estuvo junto a él, lo eligió y lo encumbró sobre sus allegados y familiares. Del mismo modo el pueblo: tiene las mismas inclinaciones que los otros pueblos, pero Dios lo ha elegido y no se aparta de él. La elección de Dios le interpela de continuo a apartarse de los delitos".

3.4. En determinar qué función cumple la evocación del antepasado epónimo en el desarrollo de la argumentación.

No es una cuestión fácil de resolver. En principio, parece haber cierta conformidad al estimar que la función de las diversas referencias a las tradiciones jacobitas en Os 12 intentarían proponer algún tipo de analogía tendiente a representa el carácter o las acciones del Israel del tiempo de Oseas.

Pero la conformidad se diluye al momento de determinar qué clase de analogía se habría pretendido -si se trata (3.4.1.) de correspondencia, (3.4.2.) de contraste o (3.4.3.) de algún otro tipo de relación (o correlación) - y -sobre todo y una vez establecida- cuál es el objetivo específico que se habría perseguido al establecerla.

Proponemos una primera presentación, a manera de ilustración, de algunas interpretaciones de los especialistas, prescindiendo por el momento de la posición que hubieren tomado respecto del presunto conocimiento que "el profeta Oseas" habría tenido de las tradiciones de Jacob según aparecen en el libro del Génesis.

3.4.1. Os 12 plantearía una (estricta) correspondencia entre el comportamiento reprobable (y/o el carácter díscolo) del ancestro Jacob y el del Israel contemporáneo a Oseas y la función de la analogía estaría al servicio de:

- Resaltar el pecado del pueblo.

Por ejemplo, sea señalando decididamente su raíz viciada y advirtiéndolo severamente ${ }^{11}$, sea denunciando las intrigas políticas de Israel por estar apoyadas en una falsa confianza en un falso dios, un dios que pudo ser derrotado incluso por un patriarca, y que se encuentra y se oye -como

${ }^{11}$ Dice J. MeJíA, Amor, pecado, alianza. Una lectura del profeta Oseas, Buenos Aires Teología. Estudios y Documentos - 1975, 122: "Teológicamente ... significa una severa advertencia al pueblo para prevenirlo contra toda soberbia y todo apoyo excesivo en su elección, puesto que procede de una raíz viciada". 
lo encontró y lo oyó Jacob en el pasado- en los ritos repugnantes de Betel ${ }^{12}$.

- Resaltar la acción salvífica gratuita de Yahweh.

Por ejemplo, mostrando que la historia culpable de Jacob es superada mediante la acción salvífica de Yahweh ${ }^{13}$.

3.4.2. Os 12 procuraría establecer un contraste entre el comportamiento (en algún punto ejemplar) del ancestro Jacob y el (reprobable) del Israel del siglo viII y la función del contraste estaría al servicio de:

- Mostrar al Israel contemporáneo al profeta a un Jacob que descubrió, al encontrarse con Dios, dónde está la verdadera fuente de la fortaleza y la riqueza ${ }^{14}$.

- Mostrar al Israel contemporáneo al profeta a un Jacob que fue un ejemplo de conversión a imitar ${ }^{15}$.

- Mostrar al Israel contemporáneo al profeta un Jacob que fue fiel a sus compromisos -"políticos"- en orden a que actúen de la misma manera ${ }^{16}$.

3.4.3. El texto estaría exponiendo algunos episodios de la vida de Jacob sin pretender ofrecer una evaluación moral de los mismos y la función de la evocación de la figura de Jacob estaría al servicio de:

${ }^{12}$ Así, por ejemplo, E. Good, Hosea, 147-148.

${ }^{13}$ Según H. WoLfF, la introducción de la analogía estaría al servicio de un interés histórico específico: mostrar que Yahweh sigue siendo el Señor, por sobre toda astucia culpable, y que su acción salvífica no queda interrumpida por los pecados.

${ }^{14}$ Así, por ejemplo, G. Emmerson, Hosea. An Israelite Prophet in Judean Perspective, Sheffield, JSOT Suppl. 28 - 1984, 129.

${ }^{15}$ Así, por ejemplo, C. Francisco, "Evil and Suffering in the Book of Hosea", 5 - 1962, 34-35; E. K. Holt, Prophesying the Past. The Use of Israel's History in the Book of Hosea, Sheffield, JSOT.S 194 - 1995, 43-46; cf. 50); S. RomERowsKI, “Le prophète Osée prêche sur l'histoire de Jacob (Osée ch. 12)", Hokhma 52 - 1993, 48 -al menos para 12,3-6-.

16 Para M. SweEney, la denuncia de la "mentira" y la traición" de “Efraim" $(12,1)$ ha de ser leída en relación con la decisión de Israel de abandonar sus acuerdos con Aram (12,12.13-15) para establecerlos con Asiria y Egipto (12,2b) y así enriquecerse $(12,9)$. Según SWEENEY, en Os 12,7, el profeta no sólo estaría llamando a un retorno a Yahweh sino también a un retorno a los compromisos políticos previamente contraídos (en particular, los de Israel con Aram). Israel mostraría su adhesión a las expectativas de Yahweh si -como Jacob- mantiene firmes sus vínculos con Aram (123). El exegeta remarca (120) que, si bien Jacob habría comenzado su vida como una figura embaucadora, su amor por (la aramea) Raquel lo habría transformado en un esposo recto y fiel, que resultó víctima fácil de explotación para su suegro Labán. 
- Destacar el protagonismo de Dios en orden a lograr un encuentro con el hombre ${ }^{17}$.

- Destacar sucesivamente a lo largo del poema diversas cualidades características de Jacob.

Por ejemplo Francis Andersen y Noel Freedman mencionan:

$\mathrm{Su}$ tenacidad desde el comienzo de su vida $(12,4 \mathrm{a})$.

Su capacidad de aferrarse a alguien y no soltarlo $(12,4 a)$.

Su fuerza, su potencia nativa, no adquirida $(12,4 b)$.

Su "éxito" tras esforzarse, tras "luchar" $(12,4 b \cdot 5 a)^{18}$.

A semejanza de Raquel, sus éxitos en sus disputas "fraternas" a causa de su relación con Dios $(12,5)^{19}$.

\section{El problema del origen de la lectura oseana de la tradición de Jacob y de su relación con los relatos del Génesis}

El peso que se le de a la presunta influencia que la versión de la tradición de Jacob que conocemos por el libro del Génesis tuvo -o no- al momento de interpretar el texto oseano -se plantee el tema explícitamente o se de por supuesto de manera más o menos implícita que así fue- ha jugado un rol clave en la decisión por la que, finalmente, se han inclinado los

${ }^{17}$ Así S. Ausín, "La tradición de Jacob en Oseas XII", EstBibl 49 - 1991, 21: “... Jacob es presentado en sus relaciones con Esaú, con el ángel, con Dios. Pero lo que se pone de relieve es el protagonismo de Dios: Dios le ha hecho superior a Esaú, le ha dado a conocer la reciedumbre y tozudez de su carácter lincluso con el cambio de nombre); le ha hecho consciente de su pequeñez ante Dios, ante quien tiene que pedir la bendición entre súplicas. Y, finalmente, le ha hecho experimentar que sus caminos se entrecruzan con los de Dios. Toda la vida del patriarca se resume en su condición de encontradizo con Dios. Aunque su comportamiento fuera reprobable, al final él y Dios terminan encontrándose".

${ }^{18}$ Si bien -indican F. Andersen - N. Freedman, Hosea. A New Translation with Introduction and Commentary, AB 14 - New York - 1980, 608- el significado del verbo śry de 12,4b-5 es incierto, parecería indicar algo que Jacob hizo “con Dios" en Penuel, probablemente "luchar" y tras una increible resistencia -al menos así lo habría entendido su contendiente- "prevalecer".

19 Para Andersen - Fredman, Hosea, 610, la rivalidad entre Lía y Raquel (particularmente, a la hora de darle hijos a Jacob) ofrecería una importante analogía para interpretar las disputas mencionadas en 2,5. Raquel se habría entendido a sí misma en su esfuerzo por ser madre en una suerte de competencia contra su hermana, en la que, aparentemente, habría vencido porque Dios respondió a sus plegarias. Este motivo fue estudiado específicamente por F. Andersen: "A Note on Genesis 30:8", JBL 88, 200. 
diversos intérpretes a propósito del sentido y significado de la recepción oseana de la figura de Jacob.

Durante muchos años, nadie cuestionó seriamente la llamada "hipótesis documental", y, con ello, la prioridad, al menos, de "la versión yavista" de la tradición patriarcal respecto de la (re)lectura oseana -e, incluso, de la elohísta (o, al menos, de alguna presunta versión "protoelohísta")-. Tampoco fue seriamente cuestionada durante mucho tiempo la certeza respecto de la originalidad básica del "material oseano". Se estaba convencido de que, salvo alguna que otra actualización redaccional, la mayor parte del texto transmitido en el Libro de Oseas procedería sustancialmente del profeta del siglo viII. Ambos consensos de antaño hoy ya no se sostienen sin más.

Se trata de una cuestión nada sencilla de resolver, pero que, al menos, según entendemos, ha de ser -si no resuelta, al menos- "blanqueada", a riesgo de recargar la ya ardua tarea de descifrar el material oseano con una "petición de principio" 20.

En general, se observa que los exegetas se han manejado en el marco de las siguientes posibilidades:

\subsection{Oseas estaría (re)leyendo la misma tradición de Jacob conocida por el libro del Génesis (y, en consecuencia, de una u otra manera dependería de ella)}

Un ejemplo emblemático de esta posición lo constituye la propuesta de Lyle Eslinger, quién -tras evaluar y discutir las importantes dificultades metodológicas implicadas- concluye, en particular, que la lectura oseana de 12,5a sería un claro caso de "exégesis intra-bíblica" (inner biblical exegesis) de Gn 32,29. Según Eslinger Oseas estaría cuestionando el significado "honroso" del nombre "Israel" que, según el libro del Génesis, se le habría impuesto tras una "titánica teomaquia". Eslinger entiende que, para Oseas, Jacob más bien habría sido un tramposo "suplantador", sometido y derrotado por Dios, y un "mensajero" (mal'ak) prevaleció sobre él.

Para William Holladay no existiría una tradición patriarcal diferente de la del Génesis sobre la que Oseas hubiera trabajado. Todo lo necesario para comprender Os 12 estaría ante nosotros, en el libro del Génesis y en el material poético paralelo en el resto del libro de Oseas.

${ }^{20}$ Esto vale sobre todo para 12,4b-5, donde las diferencias con lal menos "la letra" de) los relatos de Génesis son inocultables. 


\subsection{Oseas parece conocer una historia de Jacob que no difiere sustancialmente de los relatos transmitidos en el Génesis}

Según Wilhem Rudolph, Oseas difícilmente conoció los episodios de la vida de Jacob a los que se refiere, en una forma distinta a la que hoy día tenemos ante nosotros (prescindiendo, naturalmente, de los pasajes atribuidos al documento sacerdotal). Sin embargo, los habría evaluado y juzgado de manera diferente al común sentir popular.

Para Hans-Dieter Neef, de Os 12 surge, con alta probabilidad, que el profeta habría conocido la mayor parte de las tradiciones de Jacob. Las observaciones particulares a las historias de Jacob que Oseas habría asumido permitirían concluir un conocimiento cabal de los relatos que, en cuanto al contenido y a la forma, no diferirían considerablemente de las narraciones transmitidas en el libro del Génesis ${ }^{21}$.

Por su parte, Andrew Macintosh, si bien reconoce que hay variantes entre (su comprensión) de la versión de Oseas y los relatos de Génesis, estima improbable que de ello pudiera concluirse que Oseas hubiera utilizado una tradición diferente a la del Génesis. Para Macintosh Oseas habría conocido la historia de Jacob en una forma muy similar a la que nos ha llegado a través del libro del Génesis.

\subsection{Oseas parece conocer una tradicion que difiere en parte de la versión conocida por el Génesis}

Pieter de Boer sugiere que Oseas y sus contemporáneos habrían conocido un ordenamiento diferente de las historias de Jacob tal como aparecen en el Libro del Génesis. Además, sostiene que Oseas habría conocido historias de Jacob en las que no aparecía el dios Yahweh.

Para Edwin Good, Oseas menciona cinco episodios de la vida de Ja$\mathrm{cob}^{22}$. Pero le sería imposible decidir si Oseas conoció sólo esos cinco incidentes a los que se refiere o si conoció una tradición que conectaba estos

${ }^{21}$ Para H. NeEF, Die Heilstraditionen Israels in der Verkündigung des Propheten Hosea, BZAW 169 - Berlin-New York - 1987, 46; 39-40, al menos la tradición de Jacob tal como aparece documentada en Oseas, (1) Ya habría alcanzado su forma definitiva antes de Oseas; (2) Debió de haber sido conocida -y con un sentido claro- en tiempos de Oseas, ya que, de otro modo, sus alusiones resultarían incomprensibles.

${ }^{22}$ Esos episodios serían -según E. Good, Hosea, 149- los siguientes:

El nacimiento de Jacob como mellizo.

El encuentro conflictivo con una deidad. 
-y tal vez otros episodios- en una historia consistente. Entiende que se podría asumir que Oseas habría hecho un extracto de la tradición que conoció, ya que sus alusiones quedan separadas en dos grupos $(12,4-5$ y 12,13) y, además, por el uso temático que hace de esos incidentes.

Lo que sí cabría afirmar -estima Good- es que la historia de Jacob que conoció Oseas no habría alcanzado aún su forma final -tanto desde la perspectiva literaria como teológica- ni tampoco algún tipo de "status normativo" para la interpretación del pasado nacional. Admite la posibilidad de que Oseas hubiera podido conocer episodios relacionados con la historia de Jacob vía "tradición oral".

\subsection{Oseas maneja una tradición distinta del Génesis (¿y la versión de Génesis depende de la de Oseas?)}

Para Henrik Nyberg, Oseas, por ejemplo en 12,5a, habría manejado una tradición distinta a la de Gn 32,23-33, en la que Jacob habría sido derrotado por un "numen” (“el ángel”) y por eso, lloró y suplicó ${ }^{23}$.

Respecto de 12,5b, el exegeta sueco interpreta que, según ese versículo, el dios adorado en Betel -el Baitylos ${ }^{24}$ - encontró allí a Jacob y que, ahora, Jacob estaría hablando allí con nosotros. ${ }^{25}$

Ello hablaría a las claras de la existencia en Israel -más bien, en Betel- de un "oráculo de Jacob" asociado a una suerte de piedra "animada", a una especie de "centro de poder" localizado en la "piedra", desde dónde y mediante el cual el antepasado común hablaría con sus descendientes.

Es precisamente ese "oráculo" -y las historias acerca de Jacob que se habrían oído en ese lugar, según Nyberg, similares a las que transmite el libro del Génesis- las que habrían desatado la cólera del profeta. Esa "religiosidad" falsa, cananea y sincretista que el profeta denuncia como

Un incidente vinculado a un llanto que desembocó en el nombre de un lugar (Gn $35,8)$.

Un encuentro y diálogo con una deidad en Betel.

La huída de Jacob a Aram y su servicio a Labán por Raquel.

${ }^{23}$ Nyberg entiende que "ángel" (mal'āk) es aposición del sustantivo " "él " (no de la preposición “'èl" según lee el TM) e interpreta que se trata de un "Numen". Por eso traduce: "Und das Numen, der Engel, kämpfte und siegte".

${ }^{24}$ Según Nyberg el Bêt'ēl de Os 12,5b denotaría, exactamente como en Oseas 10,15, al Baitylos, es decir -y siguiendo a O. EISSFELDT, “Der Gott Betel”, ARW 28 1930, 17.19ss- al dios Bethel, el $\beta \alpha \iota \tau v \lambda$ os de las transcripciones griegas.

${ }^{25}$ Traducción de Os 12,5b según Nyberg: “...der Baitylos war es, der fand inn und dort redet er (jetzt) mit uns". 
"apostasía" del verdadero yavismo sería precisamente lo que reflejarían los relatos del Génesis.

Según Fabrizio Foresti (199.200), las tradiciones de Jacob tal como son conocidas por Oseas, son semejantes a las tradiciones correspondientes transmitidas por el así llamado "documento elohísta". Pero las tradiciones de Jacob transmitidas por el "Elohísta" serían más recientes, más "moralizantes" y dependientes de las de Oseas.

William Whitt señala que muchas de las diferencias del Génesis respecto de Oseas podrían ser explicadas como "reinterpretaciones" en Génesis de los dichos de Jacob citados en Oseas. Esto sugeriría sea que el autor de las historias del Génesis habría conocido y utilizado a Oseas como una de sus fuentes o que ambos, Oseas y Génesis, habrían empleado una fuente común. El material oseano mostraría que, hacia el siglo vIII habría existido, en el culto en Betel, un ciclo de historias de Jacob que abarcarían diferentes tramos de su vida. Oseas sería un importante testigo del estado de las tradiciones patriarcales en el siglo vIII, unos doscientos años antes que el "yavista" las hubiera reelaborado y unos trescientos años antes de que el "sacerdotal" les hubiera dado su forma final.

Scott Chalmers entiende que Oseas estaría citando una liturgia local de Betel para combatirla y/o parodiarla ${ }^{26}$, y que no resulta claro cuan próximas a la versión del Génesis habrían sido esas tradiciones locales.

\subsection{No sería posible detectar con exactitud cuáles fuentes habría empleado Oseas}

Dado que las alusiones a la historia de Jacob que se encuentran en Os 12 no serían citas directas y teniendo en cuenta la manera libre como el hombre oriental combina e interpreta las tradiciones antiguas y, sobre todo,

${ }^{26}$ R. S. Chalmers, "Who Is the Real El? A Reconstruction of the Prophet's Polemic in Hosea 12:5a", CBQ 68 - 2006, 624. En apoyo de su interpretación remite a Martin Buss [Os 12,4-7 contendría citas de una tradición cultual y estos dichos, un tanto presumidos, casi fanfarronadas, darían la impresión de ser citas literales, quizás levemente modificadas] y a G. DAVIES, Hosea, Eerdmans - Grand Rapids - MI - 1992 [en 0s 12,3-10 el profeta podría estar interactuando con la leyenda sagrada -hieros logos- del santuario de Betel]. Sin embargo reconoce que fue S. McKENZIE, "The Jacob Tradition in Hosea XII 4-5", VT 36 - 1986, 319-320 quien desarrolló esta idea de manera más completa. Unos años después, Chalmers desarrollaba extensamente su punto de vista en un libro: The Struggle of Yahweh and El for Hosea's Israel, Hebrew Bible Monographs 11 - Sheffield - 2008 [Oseas, especialmente entre los capítulos 11 y 13, estaría enfrascado en una polémica contra el dios adorado en Betel, al que sus oponentes estarían identificando con el dios cananeo "El”]. 
atendiendo a la independencia que los profetas han mostrado en el uso de los textos, Theodorus Vriezen entiende que no sería posible suministrar una prueba directa ni de que Oseas hubiera conocido los mismos relatos de la etapa patriarcal que hoy conocemos por el Génesis ni tampoco la opinión contraria.

Estima que, en lo que se refiere a Jacob, habría existido una tradición, conocida en términos generales, y que en lo sustancial habría sido análoga a la que actualmente disponemos.

Dado que, según su lectura, la apreciación del ancestro nacional en el Génesis y en Oseas difieren mucho entre sí y que no hubo "retoques" en el Génesis según la crítica de Oseas, se estaría en condiciones de admitir que las tradiciones de Jacob habían recibido, antes de la época de Oseas, su forma definitiva.

Steven McKenzie por su parte, si bien reconoce que no existe una diferencia radical demostrable entre la tradición de Jacob de Os 12 y la de Génesis, entiende que eso no significa necesariamente que los pasajes oseanos estuvieran basados en Génesis o en alguna de sus fuentes, ya que existen diferencias (menores) entre ambas versiones.

El origen de esas diferencias sería incierto: podrían haber surgido sea de una variante de la tradición de Jacob subyacente a Oseas, sea de una expresión popular de la tradición de Jacob para uso litúrgico, sea de una interpretación del profeta de la liturgia de Betel.

Sea lo que fuere, esta clase de incertidumbre haría que resultara imposible sacar conclusiones precisas acerca de la(s) fuente(s) subyacentes a Os 12 a propósito de la tradición de Jacob ${ }^{27}$.

\section{Al final del recorrido}

Reconocemos, por cierto que, francamente, resulta muy difícil hacerse una idea de lo que Oseas invita a evocar prescindiendo de lo que conocemos de Jacob por los relatos actuales del Génesis. Esa es la razón por la que esta cuestión ha de ser necesariamente tratada.

Pero que Oseas haya conocido las tradiciones ya escritas tal como hoy nos han llegado a través del libro del Génesis está, a nuestro juicio, (muy) lejos de haber sido probado.

Entendemos, al menos por el momento, que la segunda posición es la más moderada y convincente. No parecen suficientes los motivos para

${ }^{27}$ Aunque Steven McKenzIE, The Jacob, apoyándose en F. M. Cross, se inclina por entender que "la liturgia" de 0 s 12,4-5 se habría basado en una tradición épica. 
afirmar que Oseas hubiera conocido una tradición en relación con el ancestro nacional sustancialmente diferente a la conocida a través de los relatos del libro del Génesis.

Las diferencias entre ambas presentaciones bien pueden ser explicadas tanto por el carácter polémico de la mirada del profeta como por su perspectiva fundamentalmente homilética.

A su vez, la libertad con la que el profeta se alza contra los relatos sobre el pasado nacional nos sugiere que tales relatos no habrían alcanzado aún un "status normativo" en cuanto interpretaciones sacrales y "canónicas" del pasado nacional.

Claudia Mendoza

Buenos Aires

cmendoza@lasnieves.edu.ar 